\title{
The Implications of Converting a High-Volume Multilane Roundabout into a Turbo Roundabout
}

\author{
Zuhair Elhassy, ${ }^{1}$ Hatem Abou-Senna $\mathbb{D}^{1},{ }^{1}$ Khaled Shaaban $\mathbb{D}^{\circ},{ }^{2}$ and Essam Radwan ${ }^{1}$ \\ ${ }^{1}$ Department of Civil, Environmental, and Construction Engineering (CECE), University of Central Florida, Orlando, FL, USA \\ ${ }^{2}$ Department of Civil Engineering/Qatar Transportation and Traffic Safety Center, Qatar University, PO Box 2713, Doha, Qatar
}

Correspondence should be addressed to Khaled Shaaban; kshaaban@qu.edu.qa

Received 17 March 2019; Revised 2 June 2019; Accepted 23 August 2019; Published 10 January 2020

Guest Editor: Marco Guerrieri

Copyright (C) 2020 Zuhair Elhassy et al. This is an open access article distributed under the Creative Commons Attribution License, which permits unrestricted use, distribution, and reproduction in any medium, provided the original work is properly cited. The publication of this article was funded by Qatar National Library.

\begin{abstract}
With the growing number of vehicles utilizing roads in the city of Doha, Qatar, most intersections, particularly multilane roundabouts, have been facing traffic congestion dilemma, where traffic demand exceeds capacity. A new design for multilane roundabouts, known as a rotor turbo roundabout, was considered as an alternative to an existing highly congested multilane roundabout. The new design features spiral roadway markings and raised lane dividers which prevent maneuvering within the roundabout and eliminate cutting-offs and weavings. This design has achieved high capacity and low delay in many European countries. In this study, a traffic simulation program, VISSIM, is used to model the complex traffic operation of both the existing and proposed multilane roundabouts and to replicate the high traffic conditions and aggressive driving behavior prevalent among the Middle East countries. Three different rotor designs were examined in an attempt to have a valid comparison between the two types of roundabouts and to adhere to the standard design of the rotor roundabout without violating its essential features. The proposed designs performed slightly better on the minor approaches and managed to deliver an overall improved LOS compared to the conventional design. Major approaches, however, exhibited an increase in vehicle delay and queue lengths. The results showed that the capacity of the conventional three-lane roundabout was always superior to the capacity of the rotor roundabouts. It was concluded that rotor roundabouts may not be suitable for intersections with high demand volumes exceeding 4500 vehicles per hour, and whenever the traffic flow condition is oversaturated.
\end{abstract}

\section{Introduction}

Roundabouts have become a very common form of intersection control in many countries since the modern design was developed in the U.K. in 1966 [1]. A roundabout can be defined as a form of circular intersection in which vehicles circulate counterclockwise or clockwise, depending on whether a right-hand or left-hand traffic system, around a central island, and in which all circulating vehicles have priority over entering vehicles [1]. Modern roundabouts are considered yield-controlled intersections as entering vehicles must yield to circulating vehicles navigating through a circulatory roadway and are not allowed to enter the roundabout until they find an acceptable gap. There are mainly three different categories of roundabouts: mini-roundabouts, single roundabouts, and multilane roundabouts. Even though multilane roundabouts offer higher capacity, as compared to single and mini-roundabouts, they create more cut-off and weaving points due to lane changing behavior of drivers when entering, circulating, and exiting such roundabouts [2].

The need to provide high capacity and maintain safety levels led to the invention of a new design of multilane roundabout called "turbo" in 1996 [3]. The turbo roundabout design includes essential features such as raised lane dividers and spiral road markings. The raised lane divider obliges the driver to choose the desired lane before entry and eliminates cut-off and weaving points. Additionally, the presence of lane dividers leads to a better lane use by drivers as they have to negotiate the roundabout through a certain path indicated by lane markings and signing in order to reach their designated destination. The spiral roadway marking ensures low driving speed through the circulatory roadway, which, in turn, could increase capacity due to smaller critical gaps being accepted by entering drivers at a lower speed.

The first turbo roundabout was built in 2000 in the Netherlands, and the initial result was very satisfying. Since 
then, the turbo roundabout design has been adopted all over the Netherlands as an alternative to conventional multilane roundabouts and quickly transposed to many countries in Europe, South America, Canada, and South Africa. There are approximately 468 turbo roundabouts worldwide, 344 of which are in the Netherlands alone [4]. There are many variants of turbo roundabouts distinguished from the number of entry lanes, exit lanes, and presence of right-turn bypass lanes. For four-leg roundabouts, there are basically five variants: Basic, Egg, Knee, Spiral, and Rotor. For three-leg roundabouts, two types can be distinguished: Stretched-knee and Star roundabouts. The selection of a turbo variant depends on the traffic flow pattern and balance over roundabout's approaches. According to Dutch research, turbo roundabouts can handle a capacity of 2800-5500 passenger vehicles per hour, depending on the turbo roundabout's variant [2].

In Qatar, a country in the Middle East, multi-lane roundabouts are common and handle high traffic volumes. Also, the aggressive driving behavior is prevalent among this region, where drivers do not leave much space ahead, cut infrequently, and take advantage of very short critical gaps available within circulating flow [5-7]. In a study conducted on roundabouts in Qatar, for example, the average critical gaps were found to be 2.24 seconds, 2.55 seconds, and 2.40 seconds for single-lane, two-lane, and three-lane roundabouts, respectively [8]. These reported values are much lower than what HCM 2010 has developed and suggested, values range from 4.11 seconds to 5.19 seconds, based on the most comprehensive field study conducted at US roundabouts in 2003 [9]. The lower values of follow-up headways and/ or critical gaps result in higher capacity at intersections whose traffic operation is mainly determined based on gap acceptance such as roundabouts and led to the conversion of some roundabouts to signalized intersections in these countries [10].

The operation of an existing conventional three-lane roundabout in Qatar, The Center roundabout, is generally failing and disappointing especially during the peak hours. The measured level of service (LOS) for every approach as well as for the intersection as a whole is all F. As a result, a decision was made to convert the roundabout into a signalized intersection since the turbo design is still new and not a common alternative in Qatar. In this research, a proposed variant of a turbo roundabout is introduced to replace the existing conventional roundabout that experiences extremely high traffic volumes, significant delay, and very long queues. The purpose of this study is to consider a proper turbo roundabout design, namely a rotor turbo roundabout, to replace the existing conventional three-lane roundabout. Since the Highway Capacity Manual (HCM 2010) procedure has some limitations and is inapplicable to roundabouts with more than two entry lanes, as is the case in the study roundabout, an alternative approach for analysis is introduced, mainly relying on a stochastic micro-simulation model.

Figure 1 illustrates an aerial view of The Center roundabout. The roundabout is located at the intersection of Al Kindi St./Ibn Seena St. and Salwa Rd in Doha, Qatar. The configuration of the roundabout involves three-entry lanes and threeexit lanes on Salwa Rd., while it has two-entry and exit lanes on $\mathrm{Al}$ Kindi St, and two entry lanes and one exit lane on Ibn Seena.

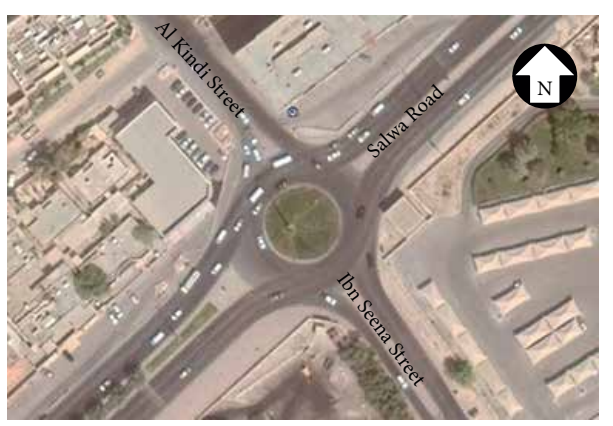

Figure 1: A close-up of the conventional multilane roundabout.

\section{Literature Review}

Since the introduction of turbo roundabouts in 1996 in the Netherlands, extensive research has been carried out to evaluate its operational performance compared to the conventional design of multilane roundabouts as well as other forms of signalized and unsignalized intersections. Several studies have reported an overall increase in capacity of turbo roundabout when compared to conventional roundabouts of similar size, while some others concluded that only in some traffic conditions, the turbo roundabout can offer higher capacity.

Yperman and Immers (2003) used Paramics, a microsimulation software package, to conclude that the turbo roundabout capacity exceeds the capacity of the conventional three-lane roundabout by $12-20 \%$, depending on traffic flow distribution over approaches. The authors added that the highest capacity can be achieved when traffic flow is equally distributed over the four legs [11].

Engelsman and Uken (2007) applied Quick-Scan's model developed by the Province of South Holland to estimate the capacity of conventional and turbo roundabouts in South Africa. The authors found that turbo roundabouts provide 25-35\% higher capacity than conventional roundabouts of similar size as long as the total entering volumes do not exceed 3000-3500 passenger cars per hour [12].

Fortuijn (2009) concluded that turbo roundabouts provide higher capacity than two-lane conventional roundabouts, due to both raised lane dividers and spiral markings, which in turn result in better use of the inner lanes of the turbo roundabout [9].

Mauro and Branco (2010) conducted a comparative analysis to identify the difference between the operational performance of turbo roundabouts and multilane conventional roundabouts in terms of capacity and delay. The authors found that the total capacity of turbo roundabouts in most cases exceed the total capacity of multilane conventional roundabouts, under undersaturated conditions of all entries and under the saturated condition of at least one entry. Additionally, the average delay is slightly lower in the turbo roundabouts, especially when the circulating flow volume is high [13].

In Slovenia, where the capacity of the conventional small two-lane roundabouts was a concern, Tollazzi et al. (2011) indicated that the Slovenian experience with turbo roundabout is very satisfying and successful. The turbo design meets Slovenian's expectations and can handle daily traffic ranging 
from 38,000 to 42,000 vehicles/day with no bottlenecks nor gridlocks [14].

Bulla and Castro (2011) stated that the use of turbo roundabouts in Bogota, Columbia, led to $12-20 \%$ increase in capacity, as compared to a two-lane conventional roundabout [15].

Giuffrè, Granà, and Marino (2012) investigated the delay incurred by vehicles entering turbo and two-lane conventional roundabouts. The authors adopted Hagring 1998 model for analyzing the two cases and concluded that turbo roundabouts perform better than conventional roundabouts when there is a high traffic volume on major approaches along with a lowto-medium traffic volume on minor approaches [16].

Baranowski (2014) concluded that the capacity of a turbo roundabout is $25-35 \%$ higher than of a two-lane conventional roundabout, due to lane assignments imposed by the presence of lane dividers [17].

Gredoska et al. (2016) evaluated the performance of three reconstructed turbo roundabouts in the Republic of Macedonia. Three different intersections, two of which were signalized and the third was unsignalized, were converted into three turbo roundabouts. The authors proved that turbo roundabouts perform better than the two signalized intersections and 2-way stop-controlled intersection in terms of capacity and average delay. The reconstruction of the three intersections, therefore, is justified by the higher operational performance [18].

Gallelli, Iuele, and Vaiana (2016) stated that the conversion of the existing conventional two-lane roundabout into a turbo roundabout in the city of Cosenza, Italy, increased the capacity by $15-84 \%$, along with minimizing the queue length by more than $90 \%$ in some cases. A microsimulation program was used to compare the operational performance between the existing two-lane roundabout and the simulated turbo roundabout [19].

In a case study conducted on a congested single-lane roundabout in Ghana, Kwakwa, and Adams (2016) used VISSIM to simulate two alternatives to the congested roundabout; double-lane conventional and egg turbo roundabouts. The authors found a 19\% increase in capacity of the egg turbo roundabout compared to the conventional double-lane roundabout of a similar size in terms of the number of entry lanes, exit lanes, and circulatory lanes. Additionally, a significant reduction in delay and queue length was obtained from the egg turbo roundabout [20].

Tollazzi, Mauro, Guerrieri, and Renčelj (2016) evaluated and compared four different alternatives to traditional double-lane roundabouts, one of which was turbo roundabouts. The authors focused on vehicles delay and created three traffic volume scenarios. Findings revealed that turbo roundabouts become superior and operate efficiently if $70 \%$ of vehicular volume on each leg makes a right turn [21].

Šarić and Lovrić (2017) aimed to evaluate the capacity of basic turbo roundabouts in Bosnia using Hagring's capacity model. Three vehicular volume scenarios on major approaches were created for analysis and evaluation: 1000, 1200, and 1500 vehicles per hour. Minor approaches volumes were incrementally raised as well. The authors concluded that the overall capacity of basic turbo roundabouts is superior to conventional two-lane roundabout's capacity under any circumstances. Finally, the authors added that minor approaches' capacity of turbo roundabouts is boosted as well [22].

All the above-mentioned studies involve the process of converting a traditional roundabout or a signalized intersection into a turbo roundabout to provide more capacity and/ or lower delay and queue lengths. In each study, one turbo roundabout variant was implemented, specifically, the basic turbo roundabout that includes double-lane entries and double-lane exits on major approaches, while it has double-lane entries and single-lane exits on minor approaches, all along with two circulatory lanes. The current study evaluates a high-volume three-lane conventional roundabout with three lanes on major approaches, dual entry lanes on minor approaches, and three full circulatory lanes, which has not been studied before. The study is an attempt to investigate the effect of converting a high-volume conventional roundabout into a turbo roundabout.

\section{Methodology}

To analyze and evaluate the operational performances of roundabouts, several capacity models have been developed worldwide. Capacity models can be primarily classified into three categories: empirical regression models, gap acceptance models, and micro-simulation models. The procedure presented in the Highway Capacity Manual (HCM 2010) is a combination of empirical regression and gap acceptance models and can be used for single and multilane roundabouts analysis [7]. The HCM 2010 model, like all other capacity models, has some limitations. Such limitations include, but not limited to, the inability to analyze roundabouts with more than two-entry lanes, two circulating lanes, and/or two-exit lanes [7]. As such, the HCM 2010 model is inapplicable to the multilane roundabout under consideration. Instead, VISSIM, a micro-simulation lane-based model developed by PTV Group, is employed in the analysis of the conventional roundabout as well as the proposed rotor turbo roundabout alternative designs.

VISSIM can model complex traffic operations at roundabouts and simulate vehicles at individual levels, and it is very sensitive to car-following and lane-changing behavior. VISSIM provides traffic engineers and transportation planners with a representative simulation of real-world driving behavior and traffic movements at roundabouts [23]. By virtue of Priority Rules and Conflict Areas features in VISSIM, traffic modelers are able to mimic and modify driver's behavior when yielding and/or stopping at conflict zones of roundabouts to reflect local driving conditions. In other words, gap acceptance parameters at unsignalized intersections, such as roundabouts, can be manually adjusted in VISSIM via Priority Rules and Conflict Areas features. Additionally, Reduced Speed Area feature grants users the ability to model normal vehicles' behavior when drivers approach roundabouts by slowing down their speed to $25-40 \mathrm{~km} / \mathrm{h}$ to start circulating the central island [21]. Furthermore, VISSIM enables traffic modelers to specify which lane drivers take through their routes from origin to destination, which is very crucial when modeling turbo 


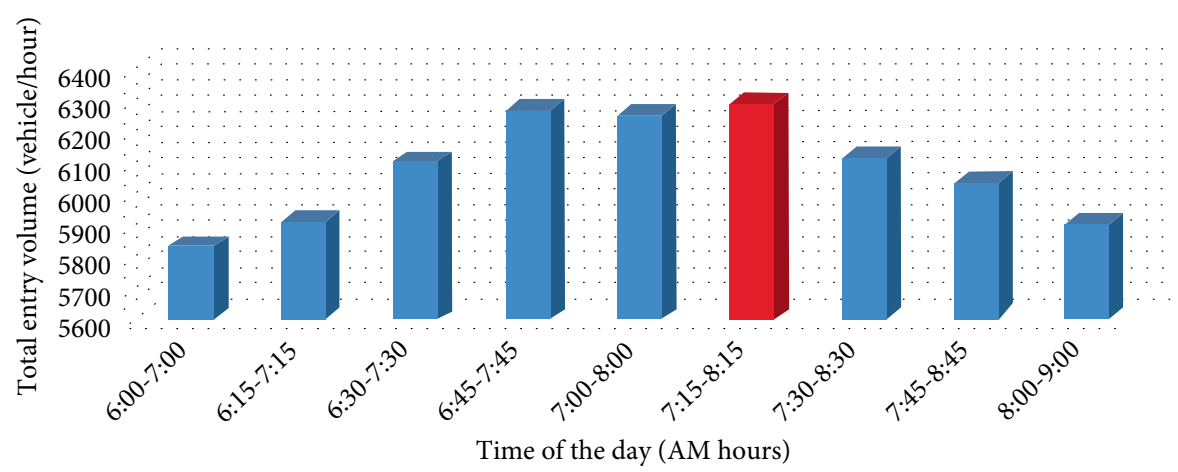

(a)

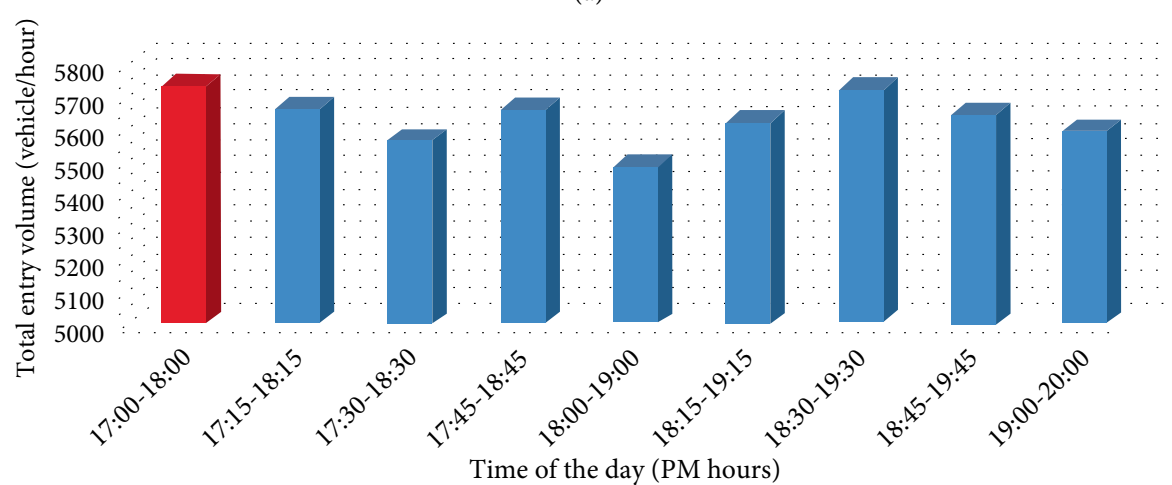

(b)

FIGURE 2: Hourly volumes for the conventional roundabout. (a) AM hourly volumes for the conventional roundabout. (b) PM hourly volumes for the conventional roundabout.

roundabouts in which no weaving or cutting-off is allowed within the circulatory roadway. Accordingly, some researchers believe that VISSIM is considered the best micro-simulation model for roundabouts [24].

3.1. Field Data Collection. Vehicular traffic turning movement counts (TMCs) used in the current study were collected using four high-quality video-recording cameras, each of which provided a bird's eye view to cover the whole roundabout in addition to the facing approach. Afterward, traffic movement counts for each vehicle class in 15-minute intervals were manually extracted and entered in spreadsheets to identify the morning and evening peak hours of the traffic flow. As can be seen in Figure 2, the AM peak hour was observed from 7:15 AM to 8:15 AM, while the PM peak hour was observed from 5:00 PM to 6:00 PM. For convenience, the AM \& PM peak hours are red-colored in Figure 2. The highest traffic hourly volume entering the roundabout occurred in the AM peak hour, with a total of 6289 vehicles, as opposed to 5734 vehicles spotted during the PM peak hour. It is noteworthy that the average heavy vehicles percentage observed at The Center roundabout was $10.45 \%$, which is very close to the corresponding national value, 9.6\%, reported for urban principal arterials [25].

A summary of the total number of vehicles entering the conventional roundabout and percentages of heavy vehicles for the AM \& PM peak hours are presented in Table 1. In addition to the total number of vehicles, each allowed traffic
TABLE 1: Number of vehicles and heavy vehicle percentage in peak hours.

\begin{tabular}{lccc}
\hline Peak hour & Time & $\begin{array}{c}\text { Peak traffic } \\
\text { volume (vph) }\end{array}$ & $\begin{array}{c}\text { Heavy vehicle } \\
(\%)\end{array}$ \\
\hline AM peak hour & $7: 15-8: 15$ & 6289 & $8.19 \%$ \\
PM peak hour & $17: 00-18: 00$ & 5734 & $12.70 \%$ \\
\hline
\end{tabular}

movement of each approach was recorded. There are four possible vehicular movements on each approach of the conventional roundabout; namely right-turn, thru, left-turn, and U-turn movements. Table 2 presents the turning movement counts (TMCs) for each approach during the AM \& PM peak hours. As illustrated in Table 3, Salwa Rd. obviously carries the vast majority of traffic flow and dominates the intersection with $72.75 \%$ and $69.05 \%$ of the total flow for the AM and PM peak hours, respectively. Finally, although no pedestrian data was collected, pedestrian volumes observed during visual inspections of the video recordings were minimal. The effect of pedestrians on traffic operation, therefore, is ignored in the study.

3.2. Video Analysis of the Existing Condition. The video recordings of the AM and PM peak hours were thoroughly monitored to capture and fully comprehend the driving behavior of traffic flow on the roundabout. In the morning peak hour, vehicles were navigating very slowly through the roundabout. Drivers left very short space headways between 
TABLE 2: Turning movement counts (TMCs) during peak hours.

\begin{tabular}{|c|c|c|c|c|c|c|}
\hline \multicolumn{7}{|c|}{ Turning movement counts (TMCs) in the AM peak hour (vph) } \\
\hline Approach & \multicolumn{6}{|c|}{ North approach (Al Kindi street) } \\
\hline Movement & $\mathrm{R}$ & $\mathrm{TH}$ & $\mathrm{L}$ & $\mathrm{U}$ & Approach total & Percentage \\
\hline Number of vehicles & 109 & 312 & 200 & 0 & 621 & $9.87 \%$ \\
\hline Approach & \multicolumn{6}{|c|}{ East approach (Salwa road) } \\
\hline Movement & $\mathrm{R}$ & TH & $\mathrm{L}$ & $\mathrm{U}$ & Approach total & Percentage \\
\hline Number of vehicles & 102 & 1560 & 539 & 1 & 2202 & $35.01 \%$ \\
\hline Approach & \multicolumn{6}{|c|}{ South approach (Ibn Seena street) } \\
\hline Movement & $\mathrm{R}$ & $\mathrm{TH}$ & $\mathrm{L}$ & $\mathrm{U}$ & Approach total & Percentage \\
\hline Number of vehicles & 510 & 292 & 282 & 0 & 1084 & $17.24 \%$ \\
\hline Approach & \multicolumn{6}{|c|}{ West approach (Aalwa road) } \\
\hline Movement & $\mathrm{R}$ & TH & $\mathrm{L}$ & $\mathrm{U}$ & Approach total & Percentage \\
\hline Number of vehicles & 97 & 1907 & 372 & 6 & 2382 & $37.88 \%$ \\
\hline Movement total & 818 & 4071 & 1393 & 7 & 6289 & $100.00 \%$ \\
\hline \multicolumn{7}{|c|}{ Traffic movement counts (TMCs) in the PM peak hour (vph) } \\
\hline Approach & \multicolumn{6}{|c|}{ North approach (Al Kindi street) } \\
\hline Movement & $\mathrm{R}$ & $\mathrm{TH}$ & $\mathrm{L}$ & $\mathrm{U}$ & Approach total & Percentage \\
\hline Number of vehicles & 138 & 391 & 266 & 0 & 795 & $13.86 \%$ \\
\hline Approach & \multicolumn{6}{|c|}{ East approach (Salwa road) } \\
\hline Movement & $\mathrm{R}$ & TH & $\mathrm{L}$ & $\mathrm{U}$ & Approach total & Percentage \\
\hline Number of vehicles & 32 & 1343 & 497 & 3 & 1875 & $32.70 \%$ \\
\hline Approach & \multicolumn{6}{|c|}{ South approach (Ibn Seena street) } \\
\hline Movement & $\mathrm{R}$ & TH & $\mathrm{L}$ & $\mathrm{U}$ & Approach total & Percentage \\
\hline Number of vehicles & 422 & 467 & 304 & 0 & 1193 & $20.81 \%$ \\
\hline Approach & \multicolumn{6}{|c|}{ West approach (Salwa road) } \\
\hline Movement & $\mathrm{R}$ & $\mathrm{TH}$ & $\mathrm{L}$ & $\mathrm{U}$ & Approach total & Percentage \\
\hline Number of vehicles & 131 & 1482 & 257 & 1 & 1871 & $32.63 \%$ \\
\hline Movement total & 723 & 3683 & 1324 & 4 & 5734 & $100.00 \%$ \\
\hline
\end{tabular}

vehicles while being in standstill conditions and even when traveling through the intersection. Importantly, motorists managed to take advantage of short critical gaps to proceed through the busy roundabout. Until some point, there were, however, no gridlocks. In the meantime, the northbound approach, Ibn Seena St., was failing due to very long queues and vehicles could not make their ways to the roundabout in the presence of extremely high demand volumes of 2618 vehicle/hour and 1957 vehicle/hour traveling westbound and eastbound along the major approaches, respectively. At 7:40 $\mathrm{AM}$, a spillback of the queue from the adjacent intersection into the westbound approach was clearly observed, causing gridlock to the westbound exit for a few minutes. Such spillback of queues into the roundabout could be attributed to poor signal coordination along the corridor. In general, those spillbacks observed during peak hours were temporary and lasted a few minutes that did not significantly affect the roundabout's operation. The traffic operation of the roundabout was mainly and negatively influenced by the extremely high traffic volumes on Salwa Rd.

3.3. Simulation Runs. Simulation results obtained by VISSIM models should represent the stochastic nature of field conditions. In other words, the average of results obtained by multiple simulation runs for a VISSIM model should represent the true average of the model itself. The
TABLE 3: Total number of entering and exiting vehicles in peak hours.

\begin{tabular}{lcccc}
\hline Movement & $\begin{array}{c}\text { Total } \\
\text { entering }\end{array}$ & $\begin{array}{c}\text { Percentage } \\
\text { of total }\end{array}$ & $\begin{array}{c}\text { Total } \\
\text { exiting }\end{array}$ & $\begin{array}{c}\text { Percentage } \\
\text { of total }\end{array}$ \\
\hline AM peak hour & $7: 15-8: 15(v p h)$ & & \\
EB & 2382 & $37.88 \%$ & 2618 & $41.63 \%$ \\
WB & 2202 & $35.01 \%$ & 1957 & $31.12 \%$ \\
NB & 1084 & $17.24 \%$ & 766 & $12.18 \%$ \\
SB & 621 & $9.87 \%$ & 948 & $15.07 \%$ \\
\hline Total & 6289 & $100.00 \%$ & 6289 & $100.00 \%$ \\
\hline PM peak hour & $17: 00-18: 00(v p h)$ & & \\
EB & 1871 & $32.63 \%$ & 2173 & $37.90 \%$ \\
WB & 1875 & $32.70 \%$ & 1786 & $31.15 \%$ \\
NB & 1193 & $20.81 \%$ & 756 & $13.18 \%$ \\
SB & 795 & $13.86 \%$ & 1019 & $17.77 \%$ \\
\hline Total & 5734 & $100.00 \%$ & 5734 & $100.00 \%$ \\
\hline \multicolumn{5}{r}{} \\
\hline
\end{tabular}

number of runs is simply the minimum sample size required to produce valid simulation results. To make sure that the number of runs conducted by VISSIM yields results that are representative of the field conditions, an initial number of ten runs with different seed numbers were first assumed to run the simulation model and calculate the average and the standard deviation of traffic volumes at each entry and exit 
TABLE 4: GEH statistic calculations for calibration's model.

\begin{tabular}{lccccccc}
\hline Movement & $(m)$ & $(c)$ & $m-c$ & $m+c$ & $(m-c)^{2}$ & $2 *(m-c)^{2}$ & GEH statistic \\
\hline NB exit & 745 & 766 & -21 & 1511 & 441 & 882 & 0.76 \\
WB exit & 1908 & 1957 & -49 & 3865 & 2401 & 1392 & 27848 \\
SB exit & 830 & 948 & -118 & 1778 & 13924 & 42632 & 7938 \\
EB exit & 2472 & 2618 & -146 & 5090 & 21316 & 3.96 \\
NB entry & 1021 & 1084 & -63 & 2105 & 3969 & 5041 & 10082 \\
WB entry & 2131 & 2202 & -71 & 4333 & 4900 & 9800 & 1.94 \\
SB entry & 551 & 621 & -70 & 1172 & 21904 & 43808 & 2.89 \\
EB entry & 2234 & 2382 & -148 & 4616 & & 3.08 \\
\hline
\end{tabular}

approach of the intersection under consideration. The analysis revealed that the ten simulation runs were satisfactory and produced acceptable distributions in the traffic arrival patterns. In general, ten runs are always recommended and conducted in VISSIM models to produce statistically valid and reliable results.

3.4. Model Calibration. The AM peak hour is used for VISSIM model's calibration. As can be clearly seen from Table 1, the total number of vehicles entering the traditional multilane roundabout is 6289 vehicles per hour, which is a way higher than the regular capacity of a six-lane divided urban arterial in the U.S. For instance, the maximum generalized peak hour directional service volume for Florida's urbanized area for Class I arterial is 3,020 vehicles per hour [26]. The study roundabout, however, carries 6289 vehicles per hour, which corresponds to the capacity of uninterrupted flow highways in the state of Florida. That is, simply, due to the difference in driver's behavior and basic saturation flow rate between the two environments which all significantly affect roadway's capacity.

To replicate the real-world driving behavior of the study roundabout in Qatar, VISSIM 11.02 is used due to its capability of modeling such aggressive driving behavior via two main models: car-following model and lane change model. Each model has its own set of parameters, all of which can be changed to produce the desired behavior. The car-following model to be used for urban and/or arterial roadways is Wiedemann 74 which includes three main parameters: average standstill distance $\left(a_{x}\right)$, additive part of safety distance $\left(b_{\text {xadd }}\right)$, and multiplicative part of safety distance $\left(b_{x m u l t}\right)$. The last two parameters determine the desired safety distance and directly impact saturation flow rates. The lane change model contains several parameters that determine lane change general behavior, cooperative lane change, advance merging, minimum front, and rear headways after lane changes, safety distance reduction factor, and much more.

In addition to driving behavior's parameters, VISSIM also allows users to mimic traffic flow operated based on gap acceptance at conflict areas via two different algorithms: Priority Rules and Conflict Areas. Both algorithms allow traffic modelers to manipulate and set gap acceptance parameters for each vehicle class separately. It should be noted that Priority Rules and Conflict Areas are applied and calibrated to reflect local gap times and headways in Qatar.

Manual calibration of VISSIM model is performed, where it is mainly a trial and error procedure. Each calibration
TABLE 5: VISSIM calibration parameters.

\begin{tabular}{lcc}
\hline VISSIM parameter & Default value & Calibrated value \\
\hline $\begin{array}{l}\text { Average standstill distance } \\
\text { Additive part of the safety }\end{array}$ & 2 meters & 1.1 meters \\
distance & 2 & 1 \\
$\begin{array}{l}\text { Multiplicative part of the } \\
\text { safety distance }\end{array}$ & 3 & 2 \\
Advanced merging & Checked & Unchecked \\
Front gap & 0.5 seconds & 0.1 seconds \\
$\begin{array}{l}\text { Rear gap } \\
\text { Safety distance factor }\end{array}$ & 0.5 seconds & 0.1 seconds \\
(Conflict areas) & 1.5 meters & 1.0 meters \\
Minimum gap time & 3 seconds & 2.5 seconds \\
\hline
\end{tabular}

parameter in VISSIM is tweaked individually, followed by entering the simulated measure of effectiveness (MOE) of each trial in a spreadsheet. When one parameter is being adjusted, all other parameters are held constant at default values. Several trials are conducted using different parameters of car-following model, lane change model, priority rules, and conflict areas until the simulation model achieves the calibration goal or target.

The main operational measure of effectiveness (MOE) for the calibration process employed in the current research is the traffic volumes. Importantly, the calibration approach used to ensure that the model replicates the existing conditions is GEH statistic. It is a commonly-used empirical formula and adopted by most departments of transportation to compare a couple of independent datasets of traffic volumes. More importantly, the calibration target is to obtain GEH statistic values less than 5.0 at each exit and entry to the study roundabout. Table 4 shows the detailed computations of GEH statistic at each individual entry and exit approach of the conventional roundabout. As presented in Table 4, the calibration of the AM model is successfully completed as indicated by GEH statistic values less than 5.0. In addition to the traffic volumes, a visual inspection of queue lengths is implemented as a secondary operational measure of effectiveness to ensure that the AM model accurately reproduces the field existing conditions. Finally, a summary of the most influential calibration parameters in VISSIM is listed in Table 5.

3.5. Model Validation. To validate the previously-calibrated VISSIM model and ensure that it accurately represents field conditions, another independent traffic volume dataset that 
TABLE 6: GEH statistic calculations for validation's model.

\begin{tabular}{lccccccc}
\hline Movement & $(m)$ & $(c)$ & $m-c$ & $m+c$ & $(m-c)^{2}$ & $2 *(m-c)^{2}$ & GEH statistic \\
\hline NB exit & 738 & 756 & -18 & 1494 & 324 & 648 & 0.66 \\
WB exit & 1751 & 1786 & -35 & 3537 & 1225 & 2450 & 0.83 \\
SB exit & 967 & 1019 & -52 & 1986 & 2704 & 5408 & 22898 \\
EB exit & 2066 & 2173 & -107 & 4239 & 11449 & 4.65 \\
NB entry & 1186 & 1193 & -7 & 2379 & 49 & 1681 & 3362 \\
WB entry & 1834 & 1875 & -41 & 3709 & 5929 & 11858 & 0.20 \\
SB entry & 718 & 795 & -77 & 1513 & 35378 & 2.80 \\
EB entry & 1738 & 1871 & -133 & 3609 & 17689 & 3.13 \\
\hline
\end{tabular}

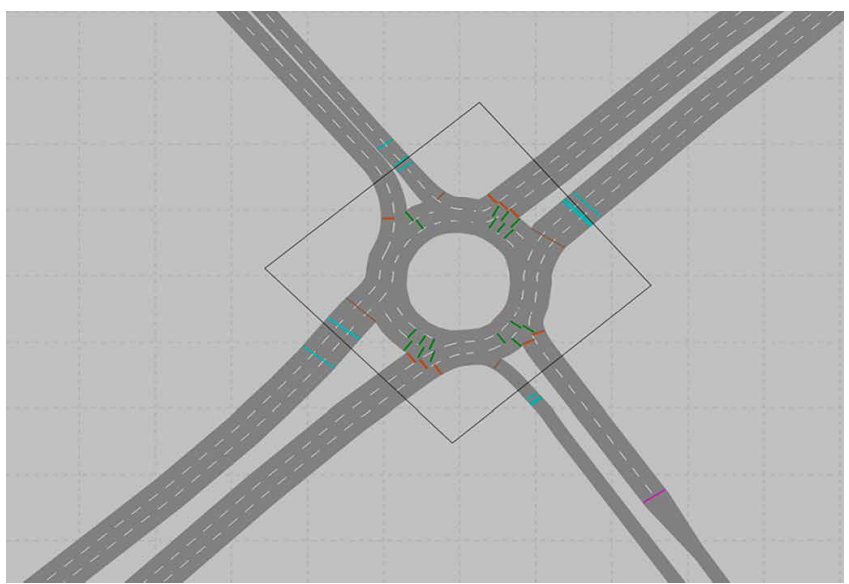

FIGURE 3: VISSIM layout of the three-lane conventional roundabout.

has never been used in the calibration process was used to re-run the calibrated model. To illustrate, the validation model was run using the PM peak hour dataset while holding all driving behavior and gap acceptance parameters constant, and thus the only parameter that is changed is the traffic volume entering the roundabout. Similar to the calibration process, the validation approach, and target used to validate the PM model is GEH statistic with values less than 5.0. Table 6 provides calculations of GEH statistic at each individual entry and exit approach of the conventional roundabout. As shown in Table 6, the PM model is successfully validated as well.

3.6. Microsimulation Analysis of the Existing Condition. After the VISSIM conventional model was calibrated and validated, few simulation parameters needed to be set prior to conducting the required number of simulation runs. First, the simulation resolution was set to ten time-steps per simulation-second. Then, the total simulation period was chosen to be 4500 seconds, covering the full AM peak hour and a 15-minute warm-up period. Finally, a series of ten simulation runs with different seed number values was completed in order to capture the inherent stochastic behavior of day-to-day traffic flow at the study roundabout. Figure 3 displays the layout and geometry of the simulated conventional model for the existing conditions in Qatar.

\section{Analysis}

4.1. Turbo Roundabout Alternative Design 1. As mentioned earlier, the rotor turbo design is proposed to replace the existing conventional design. In general, the turbo design differs in many aspects from the traditional design of multilane

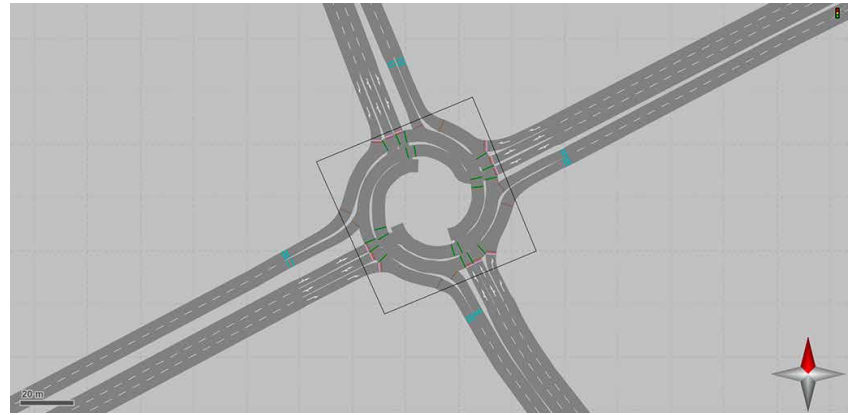

FIGURE 4: Layout and geometry of the proposed rotor roundabout (alternative design 1).

roundabouts. Such design separates the circulatory lanes by use of raised lane dividers to prevent maneuvering within these lanes, eliminating weaving and cutting-off conflicts. In addition, lane dividers result in better use of all entry lanes, as compared to traditional lane assignment adopted in the traditional design. Drivers navigating the turbo roundabout must select their lanes before entry in order to exit the roundabout from the desired leg. In some turbo variants such as the rotor, however, U-turn movements are not allowed under no circumstances. Traffic signage and lane markings, therefore, collectively play an important role in traffic operation of turbo roundabouts.

In order to achieve the highest capacity possible, the ultimate rotor layout was used which is composed of quadruple three-entry lanes and quadruple two-exit lanes. Because this layout did not match the existing roundabout, especially for the major approaches having only two entry-lanes for the through movement as opposed to three through lanes, the side street approaches were increased to offset this reduction in entry lanes on the major approach and to make a fair comparison in such a case. Although previous research results showed that the maximum rotor design capacity achieved was 4500 passenger cars per hour among all other four-leg turbo variants [2], in the presence of aggressive driving behavior environment, this number could be subject to an increase as critical gaps and minimum headways become significantly smaller than the conventional driving behavior observed in the western countries. Figure 4 depicts the general layout, geometry, and lane assignments of the proposed rotor turbo roundabout as explained above.

Traffic operational performance measures, including queue lengths, vehicles delay, level of service (LOS), and throughput volumes are extracted from VISSIM outputs for the AM peak hour of the existing and the proposed 
TABLE 7: Queue length, vehicle delay, and LOS (alternative design 1).

\begin{tabular}{|c|c|c|c|c|c|c|c|}
\hline \multirow{2}{*}{ Movement } & \multicolumn{2}{|c|}{ Queue length (m) } & \multicolumn{3}{|c|}{ Delay (second per vehicle) } & \multicolumn{2}{|c|}{ Level of service (LOS) } \\
\hline & Traditional & Rotor & Traditional & Rotor & Change $( \pm \%)$ & Traditional & Rotor \\
\hline NBR & 218.31 & 3.83 & 63.55 & 5.08 & -92.1 & $\mathrm{~F}$ & A \\
\hline NBT & 218.31 & 8.22 & 58.51 & 11.81 & -79.82 & $\mathrm{~F}$ & B \\
\hline NBL & 218.31 & 9.81 & 63.31 & 15.67 & -75.25 & $\mathrm{~F}$ & $\mathrm{C}$ \\
\hline WBR & 191.51 & 47.15 & 56.18 & 137.16 & +144.14 & $\mathrm{~F}$ & $\mathrm{~F}$ \\
\hline WBT & 191.51 & 518.61 & 54.1 & 80.02 & +47.91 & $\mathrm{~F}$ & $\mathrm{~F}$ \\
\hline WBL & 191.51 & 518.81 & 55.85 & 71.68 & +28.34 & $\mathrm{~F}$ & $\mathrm{~F}$ \\
\hline SBR & 258.94 & 0.18 & 96.73 & 2.65 & -97.26 & $\mathrm{~F}$ & A \\
\hline SBT & 258.94 & 2.04 & 97.9 & 6.55 & -93.31 & $\mathrm{~F}$ & A \\
\hline SBL & 258.94 & 3.30 & 96.6 & 8.61 & -91.09 & $\mathrm{~F}$ & $\mathrm{~A}$ \\
\hline EBR & 412 & 41.64 & 65.1 & 120.83 & +85.61 & $\mathrm{~F}$ & $\mathrm{~F}$ \\
\hline EBT & 412 & 551.31 & 59.21 & 72.51 & +22.46 & $\mathrm{~F}$ & $\mathrm{~F}$ \\
\hline EBL & 412 & 551.25 & 60.57 & 64.17 & +5.94 & $\mathrm{~F}$ & $\mathrm{~F}$ \\
\hline Roundabout & 270.19 & 180.33 & 61.62 & 48.72 & -20.93 & $\mathrm{~F}$ & $\mathrm{E}$ \\
\hline
\end{tabular}

TABLE 8: Maximum throughput (alternative design 1).

\begin{tabular}{|c|c|c|c|c|c|c|c|}
\hline \multicolumn{4}{|c|}{ Conventional roundabout } & \multicolumn{4}{|c|}{ Rotor roundabout } \\
\hline Run & Interval & Movement & Volume & Run & Interval & Movement & Volume \\
\hline Average & $900-4500$ & NB exit & 745 & Average & $900-4500$ & NB exit & 542 \\
\hline Average & $900-4500$ & WB exit & 1908 & Average & $900-4500$ & WB exit & 1219 \\
\hline Average & $900-4500$ & SB exit & 830 & Average & $900-4500$ & SB exit & 667 \\
\hline Average & $900-4500$ & EB exit & 2472 & Average & $900-4500$ & EB exit & 1708 \\
\hline Average & $900-4500$ & Total & 5955 & Average & $900-4500$ & Total & 4136 \\
\hline
\end{tabular}

roundabouts. By constructing a node around the unsignalized intersection, VISSIM calculates the delay each vehicle incurs to make it through the intersection. It is noteworthy that VISSIM assigns LOS to each traffic movement based on unsignalized intersection delay thresholds specified in HCM 2010. Furthermore, VISSIM measures the queue length for each movement in every time step specified in simulation parameters, i.e., each 0.1 simulation second in the models, in the entire analysis period and the average value is always reported. Table 7 summarizes queue lengths, vehicles delay, and LOS results obtained from the traditional and the rotor models. It is notable that U-turn movements are not allowed on the proposed design, and thus they are excluded from all comparisons. Furthermore, Table 8 presents the maximum number of vehicles each roundabout manages to handle during the AM peak hour.

In terms of vehicle delay, it can be clearly noticed from Table 7 that there is a significant decrease in delay for vehicles traveling on minor approaches, Al Kindi St. \& Ibn Seen St., with a minimum decrease of $75 \%$ for NBL movement and a maximum decrease of $97 \%$ for SBR movement. That is simply due to the higher number of entry lanes of minor approaches on the rotor roundabout, as compared to the existing traditional roundabout, resulting in a considerable improvement in the level of service for each single movement as well as for the approaches, LOS B\&A for Ibn Seena \& Al Kindi approaches, respectively. Regarding the major approaches, namely Salwa Road, however, a slight to a huge increase in vehicles delay can be observed, ranging from $6 \%$ to $144 \%$. Although such an increase in delay could make the situation much worse on Salwa Rd., the rotor roundabout is yet operated at LOS E, as compared to the failing traditional roundabout. That is to say, by looking at the interstation as a whole, the LOS demonstrates a slight amelioration from LOS F to LOS E, with reduction of 12.9 seconds $(-21 \%)$ in vehicles delay.

Another performance measure that has shown a massive improvement in minor approaches is the average queue length. As can be seen from Table 7 , the average queue length has decreased from nearly 259 meters and 218 meters to around 3 meters and 10 meters on Ibn Seena and Al Kindi St. and Ibn Seena St., respectively. However, this reduction does not apply to most movements on the major approaches, i.e., Salwa Road, where the queue lengths of eastbound and westbound vehicles have increased by nearly 140 meters and 330 meters, respectively. The only positive changes to the queue lengths occurring on Salwa Rd. are observed for the right-turning vehicles from both the westbound and eastbound approaches, each of which is able to average a queue length not exceeding 50 meters, as compared to more than 200 meters in the traditional roundabout.

In regard to the maximum throughput volumes, the conventional roundabout significantly outperformed the rotor roundabout as it can accommodate nearly 6000 vehicles during the peak hour. That is to say, the rotor roundabout under the existing demand conditions can't process more than 4136 vehicles during the peak hour due to two reasons. First, the 
TABLE 9: Queue length, vehicle delay, and LOS (alternative design 2).

\begin{tabular}{|c|c|c|c|c|c|c|}
\hline \multirow{2}{*}{ Movement } & \multicolumn{2}{|c|}{ Queue length (m) } & \multicolumn{2}{|c|}{ Delay (sec/veh) } & \multicolumn{2}{|c|}{ Level of service (LOS) } \\
\hline & Traditional & Rotor & Traditional & Rotor & Traditional & Rotor \\
\hline NBR & 218.31 & 310.64 & 63.55 & 154.92 & $\mathrm{~F}$ & $\mathrm{~F}$ \\
\hline NBT & 218.31 & 310.64 & 58.51 & 159.82 & $\mathrm{~F}$ & $\mathrm{~F}$ \\
\hline NBL & 218.31 & 310.58 & 63.31 & 137.85 & $\mathrm{~F}$ & $\mathrm{~F}$ \\
\hline WBR & 191.51 & 0.04 & 56.18 & 161.08 & $\mathrm{~F}$ & $\mathrm{~F}$ \\
\hline WBT & 191.51 & 523.35 & 54.1 & 93.97 & $\mathrm{~F}$ & $\mathrm{~F}$ \\
\hline WBL & 191.51 & 523.50 & 55.85 & 89.46 & $\mathrm{~F}$ & $\mathrm{~F}$ \\
\hline SBR & 258.94 & 8.51 & 96.73 & 13.68 & $\mathrm{~F}$ & B \\
\hline SBT & 258.94 & 8.51 & 97.9 & 13.86 & $\mathrm{~F}$ & B \\
\hline SBL & 258.94 & 0.87 & 96.6 & 4.66 & $\mathrm{~F}$ & A \\
\hline EBR & 412 & 0.05 & 65.1 & 101.47 & $\mathrm{~F}$ & $\mathrm{~F}$ \\
\hline EBT & 412 & 548.96 & 59.21 & 57.21 & $\mathrm{~F}$ & $\mathrm{~F}$ \\
\hline EBL & 412 & 548.87 & 60.57 & 50.04 & $\mathrm{~F}$ & $\mathrm{~F}$ \\
\hline Roundabout & 270.19 & 277.53 & 61.62 & 76.30 & $\mathrm{~F}$ & $\mathrm{~F}$ \\
\hline
\end{tabular}

TABLE 10: Maximum throughput (alternative design 2).

\begin{tabular}{|c|c|c|c|c|c|c|c|}
\hline \multicolumn{4}{|c|}{ Conventional roundabout } & \multicolumn{4}{|c|}{ Rotor roundabout } \\
\hline Run & Interval & Movement & Volume & Run & Interval & Movement & Volume \\
\hline Average & $900-4500$ & NB exit & 745 & Average & $900-4500$ & NB exit & 479 \\
\hline Average & $900-4500$ & WB exit & 1908 & Average & $900-4500$ & WB exit & 1102 \\
\hline Average & $900-4500$ & SB exit & 830 & Average & $900-4500$ & SB exit & 696 \\
\hline Average & $900-4500$ & EB exit & 2472 & Average & $900-4500$ & EB exit & 1921 \\
\hline Average & $900-4500$ & Total & 5955 & Average & $900-4500$ & Total & 4198 \\
\hline
\end{tabular}

oversaturated flow on the east and west approaches and the unbalanced volumes negatively impacted the total number of vehicles served during the peak hour. Second, the number of exit lanes serving the dominating traffic flow is only two lanes, as opposed to three lanes in case of the conventional roundabout. In fact, rotor turbo roundabouts can show better performance when they connect two major roads and can achieve a capacity of 4500 passenger cars per hour in normal driving conditions but with under saturated flows.

4.2. Turbo Roundabout Alternative Design 2. In this design, the ultimate rotor design was partially altered to match the existing geometry and layout of the conventional three-lane roundabout in Qatar. To illustrate, the number of exit-lanes on the major approaches were increased from two lanes to three lanes. Additionally, the number of entry lanes on the minor approaches was reduced from three lanes to two lanes only. Moreover, the southbound approach has been limited to a single-exit lane. The aforementioned major adjustments are made as an attempt to make a comparison between the two designs somewhat valid and even fair. However, we were still challenged with the two-entry through lanes on the major approaches.

In the standard rotor's design, two-entry lanes only are assigned to carry traffic volumes on each approach; one is exclusive thru lane and the other is shared left and thru lane. Since the existing throughput volumes of the major approaches are extremely high and dominating the intersection, the idea

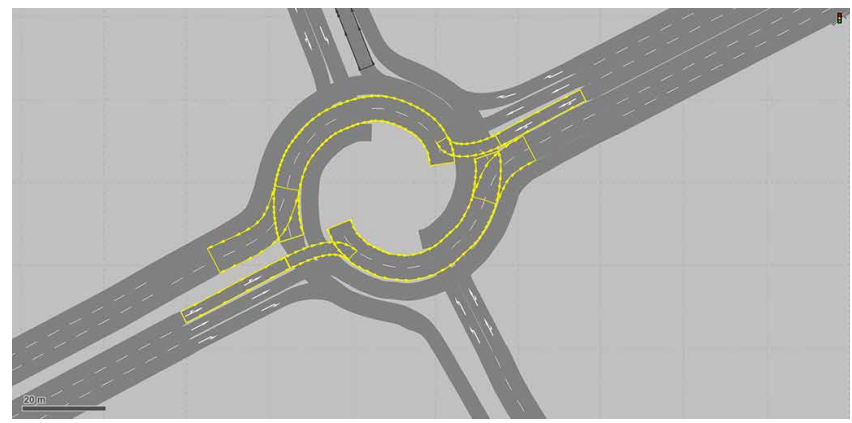

FIgURE 5: Layout and geometry of the modified rotor roundabout (alternative design 2).

of adding more circulating lanes to specifically serve major approaches comes into play and becomes necessary. Therefore, to account for such a reduction in the number of through lanes in the standard rotor's design, an inner circulating lane has been added to the inner circulatory roadway facing each major approach, i.e., E-W approaches. By doing this, one essential feature in turbo roundabouts' design that states that there are always two legs, at least, whose vehicles cross no more than two circulating lanes is not violated. Figure 5 shows the layout of the modified rotor's design, highlighting the circulatory links with one lane added on each.

Table 9 presents queue lengths, delay, and level of service obtained from VISSIM for the modified rotor roundabout. Additionally, the maximum vehicular throughput the 
TABLE 11: Queue length, vehicle delay, and LOS (alternative design 3).

\begin{tabular}{|c|c|c|c|c|c|c|}
\hline \multirow{2}{*}{ Movement } & \multicolumn{2}{|c|}{ Queue length (m) } & \multicolumn{2}{|c|}{ Delay (sec/veh) } & \multicolumn{2}{|c|}{ Level of service (LOS) } \\
\hline & Traditional & Rotor & Traditional & Rotor & Traditional & Rotor \\
\hline NBR & 218.31 & 237.57 & 63.55 & 92.29 & $\mathrm{~F}$ & $\mathrm{~F}$ \\
\hline NBT & 218.31 & 237.57 & 58.51 & 93.92 & $\mathrm{~F}$ & $\mathrm{~F}$ \\
\hline NBL & 218.31 & 237.48 & 63.31 & 102.28 & $\mathrm{~F}$ & $\mathrm{~F}$ \\
\hline WBR & 191.51 & 176.72 & 56.18 & 134.96 & $\mathrm{~F}$ & $\mathrm{~F}$ \\
\hline WBT & 191.51 & 512.77 & 54.1 & 72.98 & $\mathrm{~F}$ & $\mathrm{~F}$ \\
\hline WBL & 191.51 & 513.12 & 55.85 & 59.25 & $\mathrm{~F}$ & $\mathrm{~F}$ \\
\hline SBR & 258.94 & 10.58 & 96.73 & 15.83 & $\mathrm{~F}$ & $\mathrm{C}$ \\
\hline SBT & 258.94 & 10.58 & 97.9 & 17.38 & $\mathrm{~F}$ & $\mathrm{C}$ \\
\hline SBL & 258.94 & 0.94 & 96.6 & 4.82 & $\mathrm{~F}$ & A \\
\hline EBR & 412 & 470.64 & 65.1 & 112.39 & $\mathrm{~F}$ & $\mathrm{~F}$ \\
\hline EBT & 412 & 549.53 & 59.21 & 64.74 & $\mathrm{~F}$ & $\mathrm{~F}$ \\
\hline EBL & 412 & 549.41 & 60.57 & 51.14 & $\mathrm{~F}$ & $\mathrm{~F}$ \\
\hline Roundabout & 270.19 & 325.86 & 61.62 & 66.66 & $\mathrm{~F}$ & $\mathrm{~F}$ \\
\hline
\end{tabular}

TABLE 12: Maximum throughput (alternative design 3).

\begin{tabular}{|c|c|c|c|c|c|c|c|}
\hline \multicolumn{4}{|c|}{ Conventional roundabout } & \multicolumn{4}{|c|}{ Rotor roundabout } \\
\hline Run & Interval & Movement & Volume & Run & Interval & Movement & Volume \\
\hline Average & $900-4500$ & NB exit & 745 & Average & $900-4500$ & NB exit & 552 \\
\hline Average & $900-4500$ & WB exit & 1908 & Average & $900-4500$ & WB exit & 1385 \\
\hline Average & $900-4500$ & SB exit & 830 & Average & $900-4500$ & SB exit & 767 \\
\hline Average & $900-4500$ & EB exit & 2472 & Average & $900-4500$ & EB exit & 1920 \\
\hline Average & $900-4500$ & Total & 5955 & Average & $900-4500$ & Total & 4624 \\
\hline
\end{tabular}

modified rotor's design can handle is introduced in Table 10. By carefully looking at the results, it can be clearly seen that the modified rotor's design makes the situation even worse by experiencing a much higher delay of $61.62 \mathrm{sec} / \mathrm{veh}$, as opposed to only $48.72 \mathrm{sec} / \mathrm{veh}$ in case of the standard rotor design. Such an increase in delay is due to the negative impact of the need to cross longer distance by minor approach vehicles in order to enter the roundabout, in addition to the obvious underuse of the newly-added lane by major-road circulating vehicles. On the other hand, the maximum throughput the modified rotor roundabout can handle showed a marginal increase from 4136 to 4198 vehicles per hour.

4.3. Turbo Roundabout Alternative Design 3. In this modified design, an attempt has been made to significantly reduce the number of conflicting vehicles in front of the major approaches by (1) minimizing the number of conflicting lanes for all traffic movements in front of the major approaches to one single lane; (2) creating a new inner lane exclusively for side-streets' vehicles, i.e., N-S approaches, making left-turn at the roundabout. The new inner lane is then connected to the previously-inserted circulating double-lane. Figure 6 demonstrates the geometrical layout of the modified rotor's design. By rerouting left-turning vehicles on minor approaches as shown in Figure 6, two considerable advantages can be gained. First, the number of entering vehicles on major approaches is subject to a significant increase due to a reduction in circulating, conflicting vehicular volume. Second,

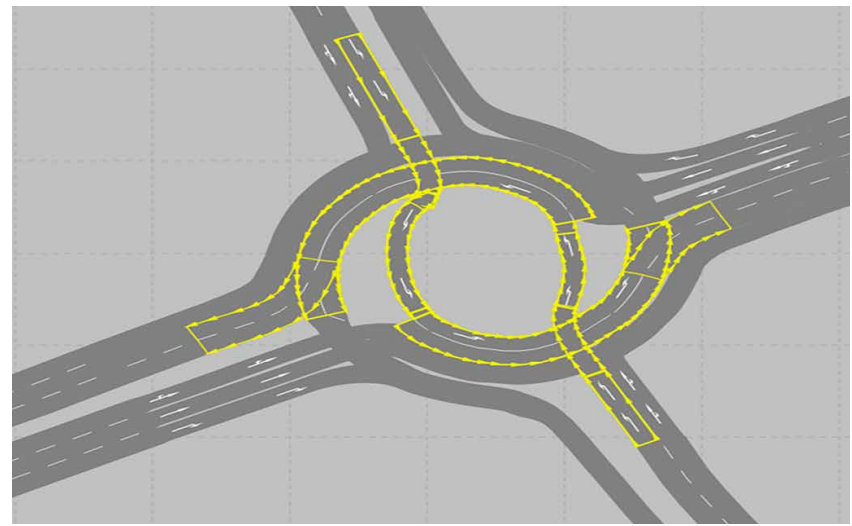

FIGURE 6: Layout and geometry of the modified rotor roundabout (alternative design 3).

the left-lane of the previously-inserted circulatory roadway can be taken advantage of by left-turning vehicles coming from the minor approaches. More importantly, to always comply with the rotor design's essential features; no lane change is applied to the previously-inserted circulatory roadway.

Table 11 presents queue lengths, delay, and level of service obtained from VISSIM for the modified rotor roundabout. Furthermore, the maximum vehicular throughput the modified rotor's design can handle is listed in Table 12. Apparently, this design substantially improves the maximum throughput of the rotor roundabout in comparison with the first and the 
second design of the rotor roundabout. In other words, the third design efficiently processes 4624 vehicles per hour, which accounts for almost $74 \%$ of the total traffic volume of the intersection. The capacity of the rotor roundabout under consideration is considered capped due to the fact that the enormous through traffic traveling on the east and west approaches can use only two entry lanes rather than three entry lanes on the conventional three-lane roundabout. Vehicles on the modified design (design 3), however, still suffer a slightly higher delay of 66.66 seconds per vehicles, as opposed to 61.62 seconds per vehicles on the conventional roundabout.

In general, the third design of the rotor roundabout efficiently achieved the highest capacity ever with a delay that is slightly higher than the conventional roundabout experiences. In terms of average queue lengths, the conventional roundabout performs much better when compared with the rotor modified design (alternative design 3 ).

\section{Conclusion}

Turbo roundabouts have never been built in Qatar, where aggressive driving behavior is very common especially in high traffic conditions. The turbo design offers high capacity and lowers vehicles delay in many European countries due to its unique features such as spiral road markings and raised lane dividers. Of the many turbo roundabout variants, the rotor turbo design that achieves the highest capacity possible among the four-legged variants is introduced and investigated as a potential alternative to the heavily congested traditional roundabout, The Center roundabout, in Doha, Qatar. Three different alternative designs were examined in order to offset the reduction in the through lanes (from three to two) on the major approach to adhere to the standard design of the rotor roundabout and its essential feature that vehicles cannot cross more than two circulating lanes. Results showed that the rotor turbo Design 1 achieved a slightly better overall level of service, LOS E, and considerably reduced the average vehicles delay of the intersection as a whole by approximately $21 \%$. Nevertheless, due to the extremely high traffic volumes on Salwa Rd., the eastbound and westbound approaches experienced an increase in delay, varying from $6 \%$ to $145 \%$. The minor approaches performed better with LOSs that varied from $\mathrm{C}$ to $\mathrm{A}$ due to the increase in entry lanes to offset the reduction in the mainline lanes. In terms of queue lengths, the rotor design is successfully able to significantly cut the queue lengths on minor approaches to very minimal levels, while the main approaches, gained queue length increases of 140 meters and 330 meters, respectively. With respect to throughput volumes, the traditional roundabout successfully handled nearly 6000 vehicles per hour and exhibited better performance as it processed nearly 1800 vehicles more than the rotor roundabout under unbalanced volume conditions.

Alternative design 2 attempted to have a valid comparison between the conventional and the rotor design with few adjustments to the standard rotor design to match the geometrical layout of the conventional three-lane roundabout. Results showed that the capacity of the three-lane roundabout is always superior to the capacity of the rotor roundabouts. In the modified rotor design 3 , the throughput increased considerably, but it never surpassed the conventional roundabout's capacity. Notably, both the rotor roundabout and the conventional roundabout, however, experienced an approximately similar delay.

Generally, it can be concluded that rotor roundabouts may not suitable for intersections with high demand volumes exceeding 4500 passenger cars per hour, and whenever the traffic flow condition is oversaturated. Rotor turbo roundabouts are mainly introduced to maintain safety levels on multilane roundabouts, but they fail to achieve comparable capacity when compared to their traditional peers. Rotor roundabouts perform exceptionally well if they operate within their capacity limits.

\section{Data Availability}

The data used to support the findings of this study are available from the corresponding author upon request.

\section{Conflicts of Interest}

The authors declare that they have no conflicts of interest.

\section{Acknowledgments}

This publication was made possible by an NPRP award [NPRP 4-1170-2-456] from the Qatar Research Fund (a member of Qatar Foundation). The statements made herein are solely the responsibility of the author. The publication of this article was funded by the Qatar National Library.

\section{References}

[1] L. Rodegerdts, J. Bansen, C. Tiesler et al., NCHRP Report 672: Roundabouts: An Informational Guide, National Academy of Sciences, Washington, DC, 2nd edition, 2010.

[2] D. Overkamp and W. Van der Wijk, Roundabouts - Application and Design: A Practical Manual, Royal HaskoningDHV, Amersfoort, The Netherlands, 2009.

[3] L. Fortuijn, "Turbo roundabouts: estimation of capacity", Transportation Research Record: Journal of the Transportation Research Board, vol. 2130, no. 1, pp. 83-92, 2009.

[4] B. Dirk de, July 2018, http://www.dirkdebaan.nl.

[5] K. Shaaban, J. S. Wood, and V. V. Gayah, "Investigating driver behavior at minor-street stop-controlled intersections in Qatar," Transportation Research Record, vol. 2663, no. 1, pp. 109-116, 2017.

[6] A. Tageldin, T. Sayed, and K. Shaaban, "Comparison of timeproximity and evasive action conflict measures: case studies from five cities," Transportation Research Record, vol. 2661, no. 1, pp. 19-29, 2017.

[7] K. Shaaban and A. Pande, "Evaluation of red-light camera enforcement using traffic violations," Journal of Traffic and Transportation Engineering (English Edition), vol. 5, no. 1, pp. 66-72, 2018. 
[8] A. Hamad and Hassan, "Investigation of gap acceptance at roundabouts in qatar," MS thesis, 2017.

[9] HCM, HCM2010: Highway capacity manual, vol. 3, Transportation Research Board of the National Academies, Washington, DC, 5th edition, 2010.

[10] K. Shaaban, H. Abou-Senna, D. Elnashar, and E. Radwan, "Assessing the impact of converting roundabouts to traffic signals on vehicle emissions along an urban arterial corridor in Qatar," Journal of the Air \& Waste Management Association, vol. 69, no. 2, pp. 178-191, 2019.

[11] I. Yperman and B. Immers, "Capacity of a turbo-roundabout determined by micro-simulation," in Proceedings of the 10th World Congress and Exhibition on Intelligent Transport Systems and Services, Madrid, Spain, 2003.

[12] J. Engelsman and M. Uken, "Turbo roundabouts as an alternative to two lane roundabouts," in Proceedings of the 26th Southern African Transport Conference (SATC 2007), Pretoria, South Africa, pp. 581-589, 2007.

[13] R. Mauro and F. Branco, "Comparative analysis of compact multilane roundabouts and turbo-roundabouts," Journal of Transportation Engineering, ASCE, vol. 136, no. 4, pp. 316-322, 2010.

[14] T. Tollazzi, S. Turnšek, and M. Renčelj, "Slovenian experiences with "turbo-roundabouts," in Proceedings of the 3rd International Conference on Roundabouts, Carmel, Indiana, 2011.

[15] L. Bulla and W. Castro, "Analysis and comparison between two-lane roundabouts and turbo roundabouts based on a road safety audit methodology and microsimulation: a case study in urban area," in Proceedings of 3rd International Conference on Road Safety and Simulation, Indianapolis, IN, 2011, http:// onlinepubs.trb.org/onlinepubs/conferences/2011/RSS/2/ Bulla,L.pdf.

[16] O. Giuffrè, A. Granà, and S. Marino, "Comparing performances of turbo-roundabouts and double-lane roundabouts," Modern Applied Science, vol. 6, no. 10, pp. 70-79, 2012.

[17] Bill Baranowski and P. E. Roundabouts USA, "Turbo Roundabout Design? Redesign of Park City's 14 Year Old," in 4th International Conference on Roundabouts-Seattle, WA April, Deer Valley Roundabout TRB, 2014.

[18] N. Gredoska, K. Bombol, and D. K. Nechoska, "An evaluation of turbo roundabouts performances: case study of the city of Ohrid," International Journal Traffic Transport Engineering, vol. 6, no. 2, pp. 196-211, 2016.

[19] V. Gallelli, T. Iuele, and R. Vaiana, "Conversion of a semi-two lanes roundabout into a turbo-roundabout: a performance comparison," Procedia Computer Science, vol. 83, pp. 393-400, 2016.

[20] O. Kwakwa and C. Adams, "Assessment of turbo and multilane roundabout alternatives to improve capacity and delay at a single lane roundabout using microsimulation model Vissim: a case study in Ghana," American Journal of Civil Engineering and Architecture, vol. 4, no. 4, pp. 106-116, 2016.

[21] T. Tollazzi, R. Mauro, M. Guerrieri, and M. Renčelj, "Comparative analysis of the four new alternative types of roundabouts: "turbo", "flower", "target", and "four-flyover" roundabout," Periodica Polytechnica Civil Engineering, vol. 60, no. 1, pp. 51-60, 2016.

[22] A. Šarić and I. Lovrić, "Multi-lane roundabout capacity evaluation," Frontiers in Built Environment, vol. 3, 2017.
[23] M. Trueblood and D. Jim, "Simulating roundabouts with VISSIM. 2nd Urban Street Symposium: Uptown, Downtown, or Small Town: Designing Urban Streets That Work Transportation Research Board; Federal Highway Administration; ITE, ITE Traffic Engineer Council, and So Cal ITE," American Society of Civil Engineers; Mack-Blackwell Rural Transportation Study Center; and US Access Board, 2003.

[24] Aaron Elias, Roundabout modeling in CORSIM, Diss University of Florida, 2009.

[25] M. Hallenbeck and B. Smith, "Vehicle volume distributions by classification. No. FHWA-PL-97-025,” 1997.

[26] Florida Department of Transportation, "FDOT Quality/Level of Service Handbook. FDOT," 2013. 


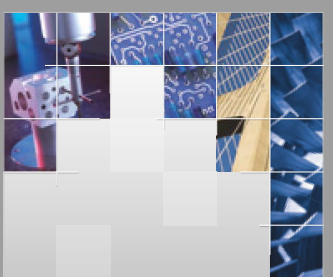

\section{Enfincering}
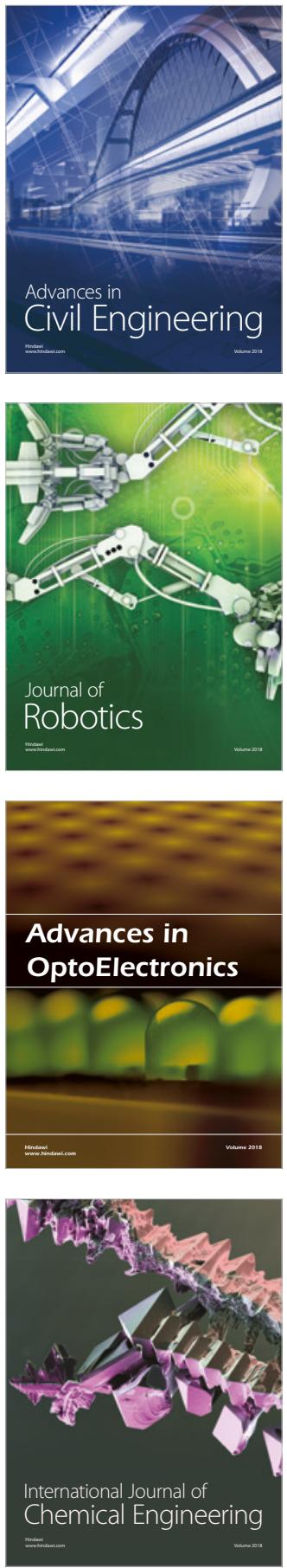

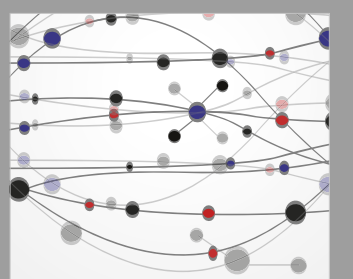

\section{Rotating \\ Machinery}

The Scientific World Journal

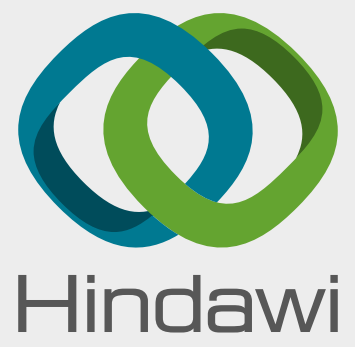

Submit your manuscripts at

www.hindawi.com
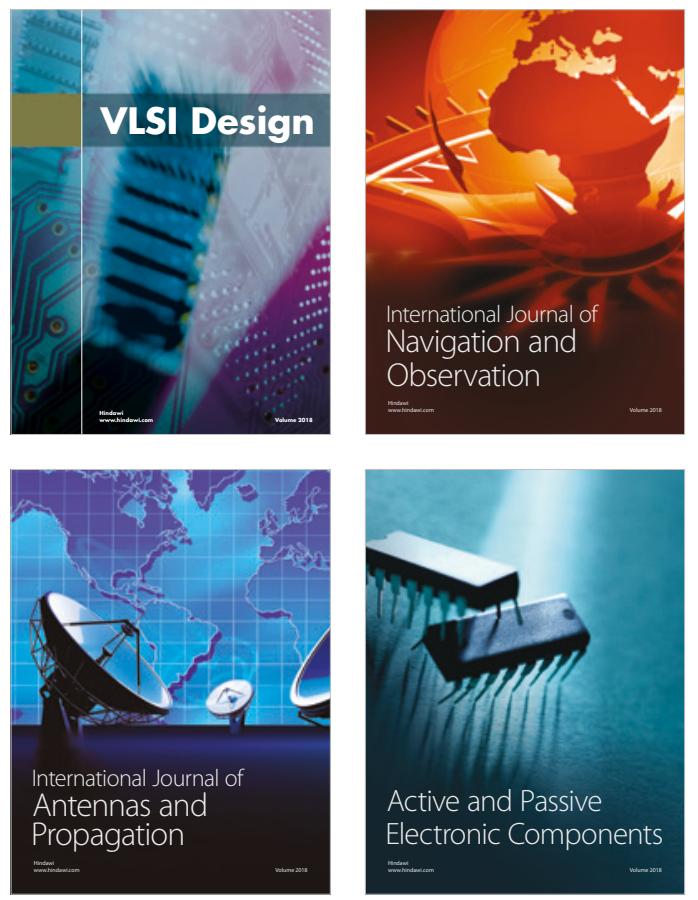
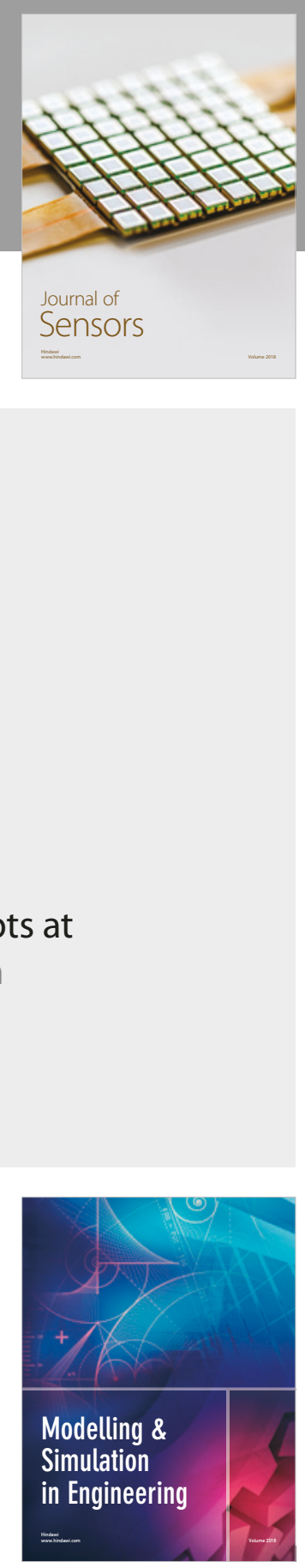

\section{Advances \\ Multimedia}
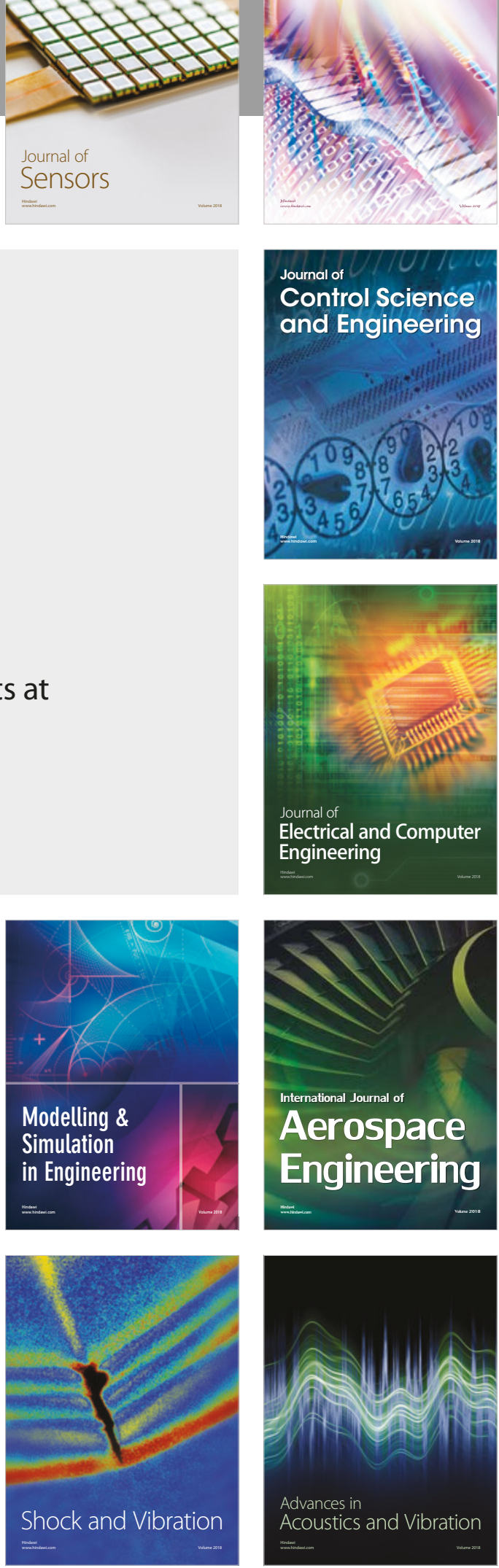